\title{
Fast-response measures to mitigate the COVID-19 health and economic impacts within the organizations: the case of Thyssenkrupp Elevator Brazil
}

\author{
Rodrigo Frank de Souza Gomes ${ }^{\mathrm{a} *}$ (D), Leandro Gauss ${ }^{\mathrm{a} * *}$ (1), Daniel Pacheco Lacerda ${ }^{\mathrm{a} * * *}$ (i) \\ aUniversidade do Vale do Rio dos Sinos, São Leopoldo, RS, Brasil \\ *rodrigofrank@edu.unisinos.br, **igauss@unisinos.br, ***dlacerda@unisinos.br
}

\begin{abstract}
Paper aims: This paper aims at investigating the efficacy of fast-response measures to mitigate the impacts of COVID-19 in an essential service organization that continued to operate despite the pandemic.

Originality: Although the number of studies associated with COVID-19 has grown exponentially, insufficient attention has been paid to how organizations should rapidly respond to overcome the trade-off between worker's health and economic activity.

Research method: A five-step case study design is carried out in this research. The efficacy of measures is assessed through the amplitude and agreement level among respondents as well as a statistical comparative analysis to evidence the significance of the results.

Main findings: Our findings indicate that the mitigation measures implemented within the factory were well-accepted by employees and empirical evidence attests to the efficacy of the actions implemented, even though further studies are needed.

Implications for theory and practice: The study expands the literature about Business Continuity Planning and highlights the Evaporating Cloud (a tool of the Theory of Constraints) as a mechanism to broaden the capacity to analyze conflicts. For practitioners, this research presents a useful body of knowledge to deal with trade-offs at the enterprise-level.

Keywords

COVID-19. Mitigation measures. Business continuity planning. Theory of constraints.
\end{abstract}

How to cite this article: Gomes, R. F. S., Gauss, L., \& Lacerda, D. P. (2021). Fast-response measures to mitigate the COVID-19 health and economic impacts within the organizations: the case of Thyssenkrupp Elevator Brazil. Production, 31, e20200062. https://doi.org/10.1590/0103-6513.20200062

Received: Jul. 01, 2020; Accepted: Jan. 19, 2021.

\section{Introduction}

"A major disaster can be defined as a natural or manmade occurrence that causes significant disruption to everyday activity and involves numerous casualties and loss of life" (Speight, 2011, p.529). This conception complies with the situation imposed by the novel coronavirus (COVID-19) which infected 83.1 million people and caused the death of more than 1.8 million people around the world up to Dec $30^{\text {th }}$, 2020 (Worldmeter, 2020). This pandemic turned into a global challenge that has been pushing the governments to minimize both the deaths and the economic impacts resulting from the viral spread (Anderson et al., 2020). As a result, aware of the devastating effects on the economy (Bruinen de Bruin et al., 2020), many countries have decided to close borders and shut down industries, businesses, and schools by establishing quarantines and lockdown periods in favor of preserving health, except for restricted essential services providers, which had to rapidly adapt their operations to deal with such unprecedented scenario and keep running. 
COVID-19 reached Latin America later than other continents. In this region, Brazil appears as the most impacted country in terms of cases and deaths (7.6 million cases and 193,940 deaths as of Dec $30^{\text {th }}$, 2020), and data are probably underestimated (The Lancet, 2020). According to a recent study by Imperial College London (2020), which analyzed the active transmission rate of COVID-19 in 48 countries, Brazil is the country with the highest rate of transmission, imposing an even higher challenge to organizations and society in general.

Since the World Health Organization (2020a) declared the COVID-19 outbreak as a pandemic, hundreds of papers on this subject have been published as an early tentative to spread information on its clinical features and implications to human health (Huang et al., 2020). However, literature about COVID-19 is quite recent and according to a search performed in the Scopus database wherein 822 articles were retrieved on Apr $24^{\text {th }}, 2020$, most of them have been performed from a health perspective and consequently do not address the economic impacts of the COVID-19 pandemic (Zhou et al., 2020; Zhu et al., 2020; Wu et al., 2020; Mackenzie \& Smith, 2020). Among those works that tackle only higher layers of economy and operations management, the enterprise-level issues are left out of the discussion (Anderson et al., 2020; Bruinen de Bruin et al., 2020). Besides, considering the organizational short-term strategies to overcome the pandemic, the studies are even more scarce.

The speed and dynamics of the pandemic require fast-response measures of governments and organizations to keep the essential operations working safely (World Health Organization, 2020b). One way to do that is through the Business Continuity Planning (BCP), which consists of creating systems of prevention and recovery to deal with potential threats to an organization. (Speight, 2011). The BCP is performed through a four-stage cycle which includes: (i) mitigation, (ii) readiness, (iii) response, and (iv) recovery. Mitigation relates to reducing and managing risks. Readiness has to do with instituting all measures that need to be in place. Response accounts for managing the emergency or crisis, while Recovery consists of identifying the requirements to return to normality once the incident is over.

Due to its intrinsic association with risk management, mitigation measures have been employed in the early stages of combatting pandemics such as Influenza, H1N1, or COVID-19 (Ciofi degli Atti et al., 2008; Tsukui, 2012; Charania and Tsuji, 2014; Ahmed et al., 2018, Anderson, et al., 2020; Bruinen de Bruin et al., 2020; Deephti et al., 2020). Therefore, this study aims at investigating the efficacy of fast-response measures to mitigate the health and economic impacts of COVID-19 within an essential service organization that continued to operate despite the pandemic. The case unit selected was a multinational leading company in the elevator industry located in the state of Rio Grande do Sul - Brazil, which deals with the conflict between shut down the operations to preserve the workers' health or keep the businesses running. Moreover, according to the federal decree 10.329/20, the elevator industry has been considered an essential service in Brazil, being part of the selected economic activities that were promptly required to maintain operations despite the pandemic of COVID-19.

Based on its empirical and investigative nature (Barratt et al., 2011), this research adopted the case study design proposed by Cauchick Miguel (2012), and employed the Evaporating Cloud (Goldratt, 1990) to structure the conflict and to explain how the organization broke the assumptions by implementing a set of fast-response mitigation measures. The research findings indicate the mitigation measures implemented were well-accepted by employees and supported the decision-making process to maintain essential services and the production of goods at the same level of the period pre-COVID, providing a safe work environment even over the most critical period of the pandemic. In addition, a statistical comparative analysis of COVID-19 cases and production level attested to the efficacy of the set of measures taken. In this context, the main contribution of this research lies in presenting a body of knowledge for practitoners to deal with trade-off at the enterprise level. Moreover, it oulines the Evaporating Cloud as a mechanism to broaden the capacity to analyze conflicts.

The remainder of this paper is structured as follows. Section 2 presents a contextual overview of COVID-19, the mitigation measures under the pandemic scenarios, and the theory of Business Continuity Planning. Section 3 outlines the research approach and methodological procedures. Section 4 presents the results of the field study. Section 5 critically analyses the research findings. Finally, Section 6 draws the conclusions, contributions, and limitations along with its future research directions.

\section{Literature review}

The literature review was organized into three subsections. A contextual overview of COVID-19 is approached in subsection 2.1. The mitigation measures under the pandemic scenarios are defined in 2.2 and finally, the Business Continuity Planning theory is outlined in subsection 2.3. 


\subsection{COVID-19: a contextual overview}

Coronavirus is an enveloped RNA virus distributed broadly among humans and causes respiratory, enteric, hepatic, and neurologic diseases (Weiss \& Leibowitz, 2011). Six coronavirus species are already known to cause human disease. Four of them are prevalent and typically cause common cold symptoms in immunocompetent individuals (Su et al., 2016). The two other strains - Severe Acute Respiratory Syndrome coronavirus (SARS-CoV) and Middle East respiratory syndrome coronavirus (MERS-CoV) - are zoonotic in origin and have been linked to sometimes fatal illness (Cui et al., 2019). SARS-CoV was the causal agent of the outbreaks in 2002 and 2003 in Guangdong Province, China (Zhong et al., 2003). MERS-CoV was the pathogen responsible for severe respiratory disease outbreaks in 2012 in the Middle East (Zaki et al., 2012).

According to Zhu et al. (2020), a novel CoV (2019-nCoV) was identified in hospitalized patients in Wuhan, China, in December 2019 and January 2020. The illness likely to have been caused by this CoV was named "novel coronavirus-infected pneumonia" (NCIP), lately named 2019 n-CoV and COVID-19. The epicenter of COVID-19 was initially in China, but the dynamics of the pandemic has changed as the virus spread out of the globe and countries failed in surveillance. In this scenario, due to the exponential growth of confirmed cases, deaths, and several political issues, Brazil becomes one of the pandemic's epicenters as highlighted by The Lancet (2020).

Several ongoing studies are still seeking efficient ways to treat the disease and flatting COVID-19 transmission (Shim et al., 2020) while vaccines are not largely available. In addition, World Health Organization (2020b) presented general recommendations to avoid an even higher growth in the number of infected cases and deaths, such as social distancing, hygiene protocols, face protection, restricted domestic and international travel, and the temporary closing of schools, trades and any business associated with agglomerations. Besides the overall recommendations, less attention was paid at the enterprise-level, especially in the operations management associated with essential services.

\subsection{Mitigation measures under pandemic scenarios}

Literature about COVID-19 is quite recent. According to a search performed in the Scopus database on Apr 24th, 2020, exponential growth in the number of publications is observed since the pandemic emerged, which represents a significant interest of the research community on the subject.

If compared to the other areas such as Medicine or Immunology, studies associating the COVID-19 with Business and Operations Management are less frequent. In this regard, the impacts of the pandemic in supply chain management were studied by lvanov and Dolgui (2020) and Yu \& Aviso (2020). Sobieralski (2020) and De Vos (2020) approached the effects of uncertainty shocks on airline employment and travel behavior, respectively. Holland et al. (2020) presented recommendations on personal protective equipment (PPE) for the emergency physician. Addo et al. (2020) examined the swings in personal PPEs online purchase behavior. Dargaville et al. (2020) highlighted the shortage of PPEs due to limited production capacity in many countries. Arora \& Srinivasan (2020) studied the impact of lockdown on the teaching and learning process. Kamel Boulos \& Geraghty (2020) pointed out a range of online applications for tracking the coronavirus epidemic. Kim (2020) investigated how the COVID-19 pandemic accelerated the structural change in consumption and digital transformation in the marketplace. Kuckertz et al. (2020) evaluated the adversity faced by startups during the crisis and suggested support initiatives to protect them from the consequences of the current lockdown.

Literature about the impacts of a pandemic is more often associated with Influenza. In this research stream, Qualls et al. (2017) presented recommendations on the use of personal, community, and environmental non-pharmaceutical interventions to prevent Influenza pandemic in the US. Ciofi degli Atti et al. (2008) evaluated the diffusion of the Influenza pandemic in ltaly and the impact of various control measures. Blendon et al. (2008) showed that community mitigation measures could cause problems for people with lower incomes and racial or ethnic minorities. Beeler et al. (2011) developed an estimation for the transmission risk using a simulation experiment. Fong et al. (2020) conducted systematic reviews of multiple mitigation measures.

Although some studies presented mitigation measures for pandemic scenarios, most are associated with public health, leaving the economic impacts out of the discussion. In this context, Ahmed et al. (2018) indicated that social distancing in non-healthcare workplaces reduced the overall as well as the peak number of Influenza cases. Concerning the COVID-19, Anderson et al. (2020) studied how country-based mitigation measures influenced the course of the pandemic. Bruinen de Bruin et al. (2020) presented an analysis of risk mitigation measures taken by countries around the world facing the current COVID-19 outbreak. Deephti et al. (2020) approached the PPE usage as pivotal in the prevention of COVID-19. Among these works, only higher layers of economy and operations management are tackled, not sufficiently examining the impacts of the COVID-19 pandemic at 
the enterprise-level. Moreover, considering the organizational short-term strategies to overcome the pandemic, the studies are even more scarce. This is the research gap the present work aims to bridge.

\subsection{Business Continuity Planning (BCP)}

"Business continuity (BC) is a management process that identifies potential factors that threaten an organization and provides a framework for building resilience and the capability for effective response" (Speight, 2011, p.529). According to Cerullo and Cerullo (2004), a BCP is designed to avoid or mitigate risks, to reduce the impact of a crisis, and to reduce the time to restore conditions to a state of "business as usual".

BC is often applied for mitigation of emergencies, crises, and disasters as it approaches subjects like risk management, crisis management programs, training, organizational safety culture, and planning. Business continuity planning (BCP), in turn, is a management mechanism to support the execution. According to Borodziz (2005), $\mathrm{BCP}$ is about achieving a balance between preparing for situations in which contingency plans will have to be used, while at the same time doing everything conceivable to stop them ever having to be used. Speight (2011) argues that BCP is the aspect of business continuity management that establishes what is vital for an organization's survival following a major disaster affecting normal operations and be viewed as a four-stage cycle.

Particularly at the enterprise level, mitigation plays an important role in business continuity planning since every organization needs to develop a comprehensive BCP based on its unique situation (Cerullo \& Cerullo, 2004). As it primarily deals with emergencies, disasters, or critical situations, mitigation is about managing risks based on an adequate and timely set of measures that need to be put in place to avoid all the threats associated with the emergency. In short, it needs to work in practice and not only in theory (Lindström et al., 2010). Readiness, in turn, is part of the BCP associated with the planning of the measures. Organizations should be prepared for emergencies. However, to deal with unprecedented scenarios as COVID-19, even developed countries have failed on that. The third stage is the Response, which means managing the crisis. 1t's how the organization structure itself to deal with the crisis already established during the entire period of instability. As the last stage, Recovery is associated with the requirements to return to normality once the crisis is over.

Despite the BCP framework provides a structure of risk management and crisis response, Speight (2011) argues that each firm can choose its strategies regarding the limitation of risk concerning its assets. In the COVID-19 scenario, identify and implement effective mitigation measures has been a quite relevant aspect to business and operations management.

\section{Research design}

This work aims at evaluating the efficacy of fast-response measures to mitigate the health and economic impacts of COVID-19 within an essential service organization that continued to operate during the pandemic. Due to its empirical and investigative nature (Barratt et al., 2011), this research adopted the five-step methodology for the case study design proposed by Cauchick Miguel (2012) as showed in Figure 1.

The process started by defining the fast-response measures to mitigate the health and economic impacts of COVID-19 within the organization as the core research subject (step 1.1). Then, in step 1.2, a literature review, analysis, and synthesis on the following issues were performed as recommended by Morandi \& Camargo (2015): (i) overview about COVID-19, (ii) mitigation measures under the pandemic scenarios, and (iii) Business Continuity Planning. As presented in Section 2, these topics revealed the transmission potential and severity of COVID-19 (Shim et al., 2020), the relevance of Brazil as one of the pandemic's epicenters as highlighted by The Lancet (2020), the lack of studies on safety mitigation measures at an enterprise-level and how BCP should be employed to mitigate emergencies such as the pandemic of COVID-19. The conceptual-theoretical framework retrieved from step 1.2 provided the foundations for establishing the research proposition in step 1.3, which consisted of evaluating the efficacy of fast-response measures to mitigate the health and economic impacts of COVID-19 within the organizations.

Step 2.1 accounted for selecting the case and the unit of analysis based on Yin (2018). The case selected was the plant of the Thyssenkrupp Elevator located in the city of Guaíba - the state of Rio Grande do Sul - Brazil. Thyssenkrupp is a multinational leading company in the elevator industry throughout the Americas (Thyssenkrupp Elevator, 2020).

The unit of analysis, in turn, was the implementation of the fast-response mitigation measures against COVID-19 carried out by the company since the beginning of March 2020. The case was selected based on the following reasons: (i) the company is the largest elevator producer in the Americas; (ii) it is located in Brazil, the country presenting the highest rate of transmission of COVID-19 so far; (iii) the company not only produces 


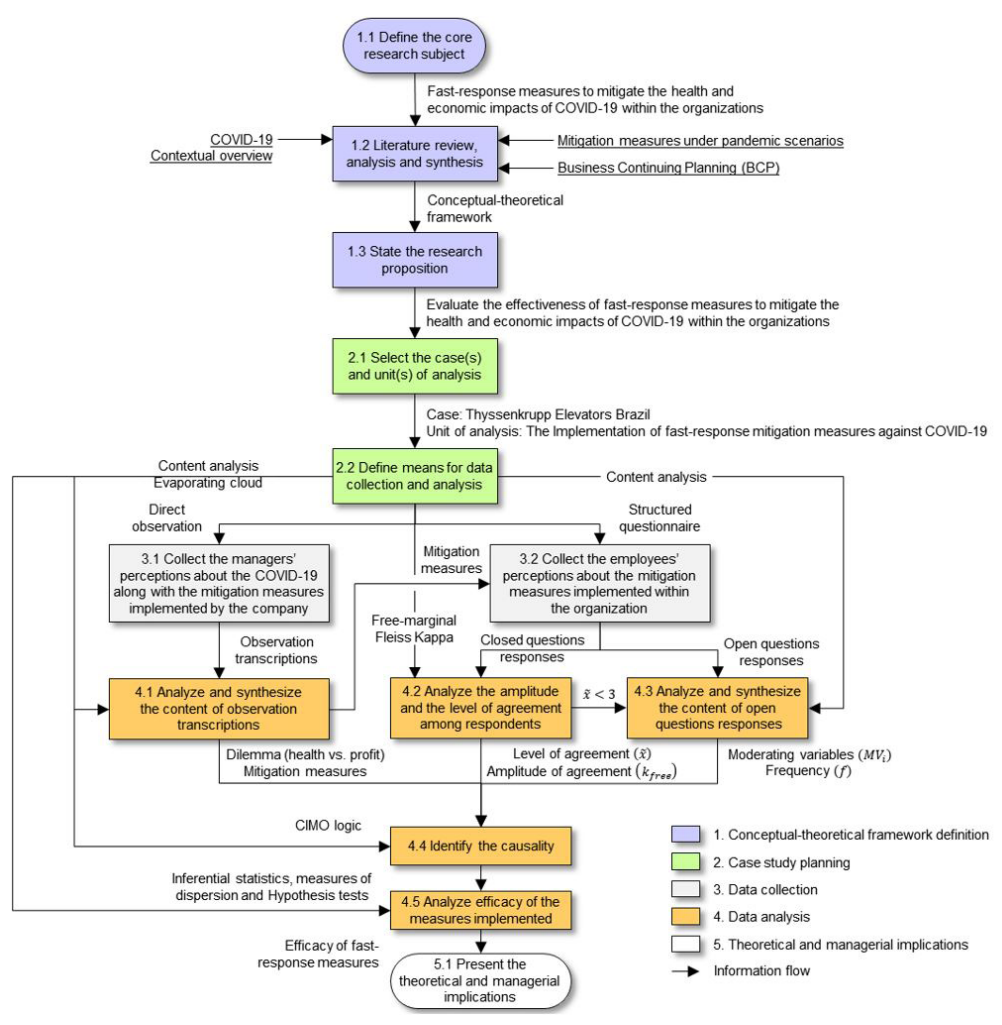

Figure 1. Research design diagram.

goods but also provides services through Latin America, and (iv) the elevator industry is considered an essential service in Brazil and also can adequately represent organizations that primarily had to take measures to keep the operations running, reaching this research interest. Concerning the unit of analysis, it was chosen because it consisted of a set of fast-response initiatives, grounded on pragmatic validity, with high potential replicability to other companies and fields (van Aken et al., 2016). Moreover, a single-case study is appropriate in several circumstances, such as to confirm, contest, or extend a well-formulated theory, such as BCP in the context of COVID-19.

The next issue was to define the means for data collection and analysis in step 2.2 (Cauchick Miguel, 2012). This process was conducted in the period of April $13^{\text {th }}$ and $30^{\text {th }}$, subdivided into two main streams regarding the managers' and employees' perspectives as showed in Figure 1. In the first stream (step 3.1), the managers' perceptions about the health and economic impacts of COVID-19 within the organization along with the mitigation measures adopted by them were captured through direct observations according to Kazemzadeh et al. (2009). The observations were transcripted and then analyzed through content analysis proposed by Bardin (1993) in step 4.1. One of the outputs of this step was the dilemma between preserving the workers' health versus the need for generating profit in any scenario, which was structured using the Evaporating Cloud (EC) (Figure 2), a logical diagram of the Theory of Constraints Thinking Process (Goldratt, 1990) used to understand a dilemma and to provide ideas of what can be changed to break the assumptions that compose the conflict and resolve the core problem (Kim et al., 2008; Pacheco Lacerda et al., 2010).

EC is composed of five entities structured to represent the conflict. The entity D represents what one out the two parties needs and D' what the other party wants. According to Andersen et al. (2013) and Eidelwein et al. (2017), these two entities must conflict either because they are mutually exclusive or due to resource contention, that is, organizations cannot afford to do both. The structure of a cloud shows that each party's want is necessary to satisfy a specific need denoted by entities B and C. Besides, both needs must be met to achieve the parties' common goal, denoted by entity A. In other words, these two needs are necessary conditions for accomplishing the common objective

The other output was the set of nine mitigation measures adopted by the organization as a tentative to mitigate the potential effects of COVID-19 on its operations based on general recommendations provided by WHO, national authorities, and experts on Health and Safety. 


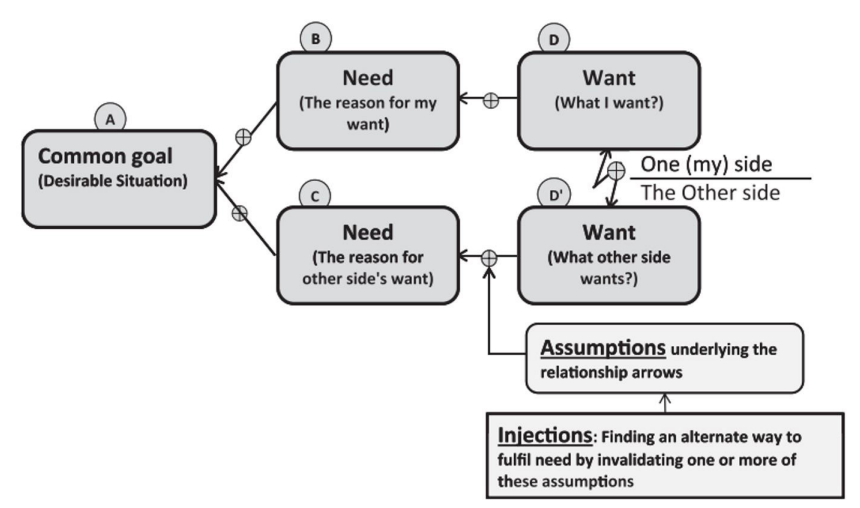

Figure 2. Evaporating cloud's structure Andersen et al. (2013).

One of the mitigation measures accounted for home office policy. Therefore, among those 753 direct employees integrating the plant, only 520 continued to work in person, while the remaining ones started holding home office activities. In the second stream, from the 520 employees, a non-probabilistic sampling was composed of 105 individuals that responded to the survey considering the timeline to collect the data (Malhotra \& Birks, 2007). The sampling was decomposed into five groups concerning the area each person worked for as shown in Table 1.

In step 3.2, the respondents had their perceptions about the nine mitigation measures implemented by the company captured through a questionnaire composed of closed and open questions, as presented in Appendix A (Forza, 2002). After data collection, the Median ( $\tilde{x}$ ) (Montgomery \& Runger, 2011) and the Free-Marginal Multi-rater Kappa $\left(k_{\text {free }}\right)$ (Randolph, 2005) were calculated for each closed question in step 4.2. For the open questions, in turn, the Content Analysis was used to derive the moderating variables $\left(M V_{i}\right)$ and its respective frequencies $(f)$ in step 4.3 (Bardin, 1993). In this context, the $\tilde{x}$ measures the amplitude of agreement, $k_{\text {free }}$ measures the level of agreement among the respondents, and $f$ measures how often the moderating variables $\left(M V_{i}\right)$, supposed to reduce the amplitude of agreement, occur. Table 2 presents four possible scenarios and their respective actions resulting from the participants' opinions.

Right after, in step 4.4, the outputs of steps 4.1, 4.2, and 4.3 were combined into a CIMO logic, which represents a combination of a problematic Context, for which the design proposition suggests a certain Intervention type, to produce, through specified generative Mechanisms, the intended Outcome(s) (Denyer et al., 2008). The design propositions seek to generate a mode 2 of knowledge, where solutions are sought for organizations and which go beyond the boundaries of a specific discipline (Veit et al., 2017).

In step 4.5, a comparative analysis of COVID-19 cases in Brazil, the state of Rio Grande do Sul, and the case unit was carried out based on data from Feb $25^{\text {th }}$ up to Dec $31^{\text {st }}, 2020$. As a preliminary analysis, ShapiroWilk and Kolmogorov-Smirnov tests were performed to verify the normality in each group. Then, a T-test or

Table 1. Groups of respondents.

\begin{tabular}{clccc}
\hline Group & \multicolumn{1}{c}{ Areas } & Employees on-site & \# of Respondents & \% \\
\hline 1 & Administrative and Commercial (HR, Legal, Purchasing, Quality, and Sales) & 58 & 18 & 31.03 \\
2 & Engineering (Industrial, Projects, Technical Support, and Specification) & 110 & 20 & 18.18 \\
3 & Management (Coordinators, Managers, and Directors) & 29 & 18 & 62.02 \\
4 & Production and logistics & 285 & 45 & 15.8 \\
5 & Others (Not listed into other categories) & 38 & 4 & 10.52 \\
Total & & 520 & 105 & 20.19 \\
\hline
\end{tabular}

Table 2. Scenarios and actions resulting from respondents' opinions.

\begin{tabular}{cc}
\hline Conditions & Action \\
\hline$\tilde{x} \geq 3$ and $k_{\text {free }} \geq 0.41$ & No identification of moderating variables $\left(M V_{i}\right)$ is required. \\
$\tilde{x}<3$ and $k_{\text {free }} \geq 0.41$ & Identification of moderating variables $\left(M V_{i}\right)$ is required. \\
$\tilde{x} \geq 3$ and $k_{\text {free }}<0.41$ & No identification of moderating variables $\left(M V_{i}\right)$ is required. \\
$\tilde{x}<3$ and $k_{\text {free }}<0.41$ & ldentification of moderating variables $\left(M V_{i}\right)$ is required. \\
\hline
\end{tabular}


Kruskal-Wallis test is employed according to the characteristics found in the previous step. A similar analysis was conducted to evaluate the production level between 2019 and 2020, to attest the efficacy of the measures also from the business perspective. For this evaluation, it was selected the period between april and december since the mitigation measures were implemented in March 2020. Finally, in step 5.1, the intervention was analyzed and discussed against the dilemma imposed by the COVID-19 pandemic, and its theoretical and managerial implications are provided. The results of this process are highlighted and discussed in the next sections.

\section{Results}

The conflicting situation faced by the Thyssenkrupp managers is depicted in the form of Evaporating Cloud in Figure 3. On one side, the organization wanted to preserve the health of its employees based on two assumptions: (i) the worker's health is an unquestionable priority, and (ii) the workplace is not safe enough against COVID-19. On the other side, the organization believed they should operate and generate profit in any scenario, a conception grounded on the following presupposes: (i) the urban transportation depends on the elevators, (ii) the elevators require uninterrupted services, and (iii) the organization cannot afford its costs without generating revenue.

From both sides, the common goal was to have the organization 100\% productive in a healthy and safe work environment. However, due to the dilemma imposed by the pandemic, there were two ways of accomplishing the desirable situation. The first was to temporarily shut down the factory and suspending the services. This perspective assumes social distancing as the best strategy to prevent COVID-19 contaminations and follows the WHO directives. The second was the opposite, the employees should continue to work, given the fact they are necessary for producing the goods and services, and the government initiatives are insufficient to deal with the economic impacts of the pandemic.

The elevator industry was considered essential in Brazil (Brasil, 2020). Therefore Thyssenkrupp decided to implement a set of fast-response mitigation measures to keep the factory and services running under the pandemic. The mitigation measures (MM) consisted of management initiatives which were abductively defined as a tentative to invalidate the assumptions of "the workplace is not safe enough against COVID-19" and "social distancing is the best way to prevent COVID-19", as shown in Table 3.

All mitigation measures were implemented in a quite short timeline, starting on Mar $16^{\text {th }}, 2020$. Since the employees were the main affected part, their opinions were captured through a questionnaire after the implementation phase. The results are summarized in Table 4, wherein the hierarchy between mitigation measures and moderating variables is depicted. The underlined numbers presented in Table 4 point out those values below the acceptable threshold adopted in this research, i.e. $\tilde{x}<3$ or $k_{\text {free }}<0.41$. Besides that, the characters within parentheses indicate to which question the mitigation measure is related.

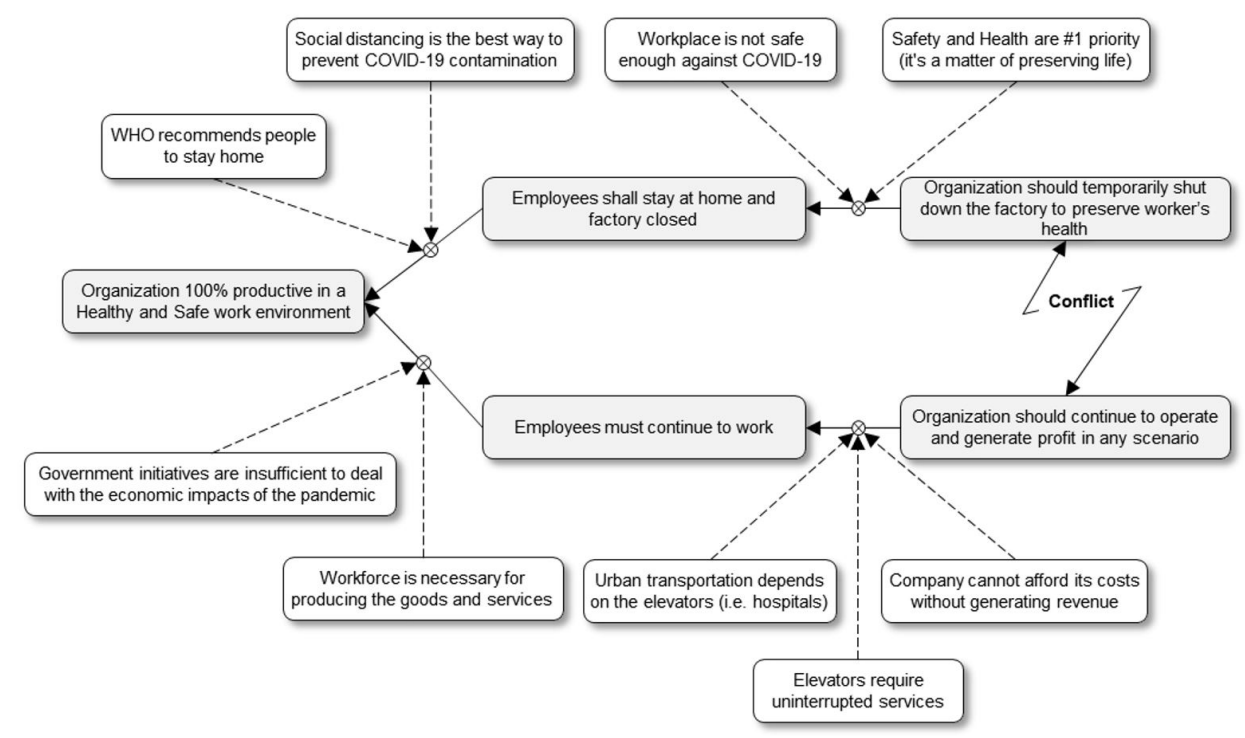

Figure 3. Evaporating Cloud - conflicting situation faced by Thyssenkrupp managers. 
Table 3. Set of mitigation measures.

\begin{tabular}{|c|c|c|}
\hline Code & Mitigation measure & Definition \\
\hline MM1 & Crisis Management Team (CMT) & $\begin{array}{l}\text { A multi-disciplinary group of employees composed of senior executives } \\
\text { (Legal expert (LEX); Procurement and Supply Management (PSM); } \\
\text { Occupational Health and Safety (OHS)) to coordinate the fast-response } \\
\text { actions against COVID-19 spread. }\end{array}$ \\
\hline MM2 & Directives for travel restriction and $\mathrm{H} \& \mathrm{~S}$ protocols for travelers & $\begin{array}{l}\text { Directives for travel restrictions and protocols to travelers arriving from risky } \\
\text { areas. }\end{array}$ \\
\hline MM3 & General Protocol for Health and Safety at work & $\begin{array}{l}\text { General recommendations and protocols for personal hygiene, suspected } \\
\text { cases, confirmed cases, home office policy, social distancing definition for } \\
\text { employees into risky groups (age of 60+, cardio-respiratory diseases, and } \\
\text { some others). }\end{array}$ \\
\hline MM4 & Temperature screening & $\begin{array}{l}\text { Daily routine at the factory's entry, wherein } 100 \% \text { of employees or visitants } \\
\text { is asked to have the body temperature screened. }\end{array}$ \\
\hline MM5 & OHS Protocol for field and 'in office' work & $\begin{array}{l}\text { Protocol and guidelines for field services (maintenance and installation) } \\
\text { and 'in office' work. }\end{array}$ \\
\hline MM6 & Protocol for N95 masks and other PPEs. & $\begin{array}{l}\text { Protocol for the use and application of N95, face shields, and face masks, } \\
\text { including table of risk services' level. }\end{array}$ \\
\hline MM7 & $\begin{array}{l}\text { Protocol for transportation and changes in the canteen lay- } \\
\text { out. }\end{array}$ & $\begin{array}{l}\text { Protocol for new routines in commuting (in company collective } \\
\text { transportation). }\end{array}$ \\
\hline MM8 & APP for tracking health self-assessment and B.1. dashboard & $\begin{array}{l}\text { An app for tracking the health self-assessment of employees interested to } \\
\text { report how they are feeling. }\end{array}$ \\
\hline MM9 & Temporary reduction in production level & $\begin{array}{l}50 \% \text { reduction in production levels for two weeks from March } 16^{\text {th }} \text { to } \\
\text { implement appropriate mitigation measures. }\end{array}$ \\
\hline
\end{tabular}

In general, the set of fast-response mitigation measures were well accepted by employees. It can be seen by the highest amplitude of agreement $(\tilde{x}=4)$, and the moderate level of agreement $\left(k_{\text {free }}=0.46\right)$ achieved among raters (Landis \& Koch, 1977). From the set of measures, the MM2, which accounts for travel restrictions, was the most well-rated $\left(\tilde{x}=4\right.$ and $\left.k_{\text {free }}=0.79\right)$. The MM1, MM5, MM8, and MM9, in turn, did not follow the same fashion $\left(k_{\text {free }}<0.41\right)$. This pattern was also noticed in groups 4 and 5 , which presented discrepancies if compared to others. For those measures not achieving the threshold, the moderating variables presented in Table 5, were used as inputs for improvement.

Each mitigation measure contributed as a fast response to obtain only one confirmed case of COVID-19 within the company during the first 120 days (up to Jun $25^{\text {th }}, 2020$ ), while official data (Coronavirus Brasil, 2020) showed 23,060 confirmed cases in the Rio Grande do Sul - the state of Brazil where the plant is located. Considering the first 120 days as a critical period of the pandemic, and all the risks involved in having hundreds of employees commuting and working in person at the plant during such a challengeable period, this result, among other business $\mathrm{KPl}$, e.g. production volume, attests to the efficacy of the measures taken, which have their contribution presented in the form of a CIMO logic in Table 6.

As of the end of 2020, the results also demonstrated that the organization reported better figures when compared to both national and regional official data in both periods analyzed (Table 7). While official data accounted for an exponential increase of cases, no similar tendency was perceived in the case unit data. Based on the comparative analysis of COVID figures of Brazil (BR), the state of Rio Grande do Sul (RS), and the case unit (TK), our findings indicated heterogeneously between the data from these three samples through the application of the Kolmogorov-Smirnov test, since the level of significance ( $p$-value) was much lower than 5\% in all cases for with a confidence interval of 95\%.

Since the population of each sample is significantly different, data from the period Feb $25^{\text {th }}$ to Dec $31^{\text {st }}$, $2020(n=311)$ was converted into the rate that is the number of daily cases for every 500 people. Due to the inexistence of normality, a non-parametric test Kruskal-Wallis was performed and results are summarized in Table 8 . The test intended to verify the homogeneity of the medians into the three groups. The result retrieved a p-value $<2.2 \mathrm{e}-16$ based on a confidence interval of 95\% and indicated that the hypothesis of homogeneity should be rejected since at least one out of the three groups had a different median. Then, the Dunn post-hoc test was performed as it is indicated to identify patterns between groups.

Considering the data shown in Table 8, only when it was compared the rate of daily cases of COVID-19 in Brazil (BR) and the state of Rio Grande do Sul (RS), the results indicated homogeneity. However, whenever BR or $\mathrm{RS}$ is compared to the case unit (TK), data are heterogeneous. This reflects that due to the mitigation measures implemented, new cases of COVID within the company do not follow the general pattern.

Especially from the perspective of the first 120 days since the beginning of the pandemic, the set of mitigation measures was critical to sustain the business and to maintain the factory running. Regarding the whole year, the figures attest to an effective business model to face the impacts of COVID-19. First, because even considering 


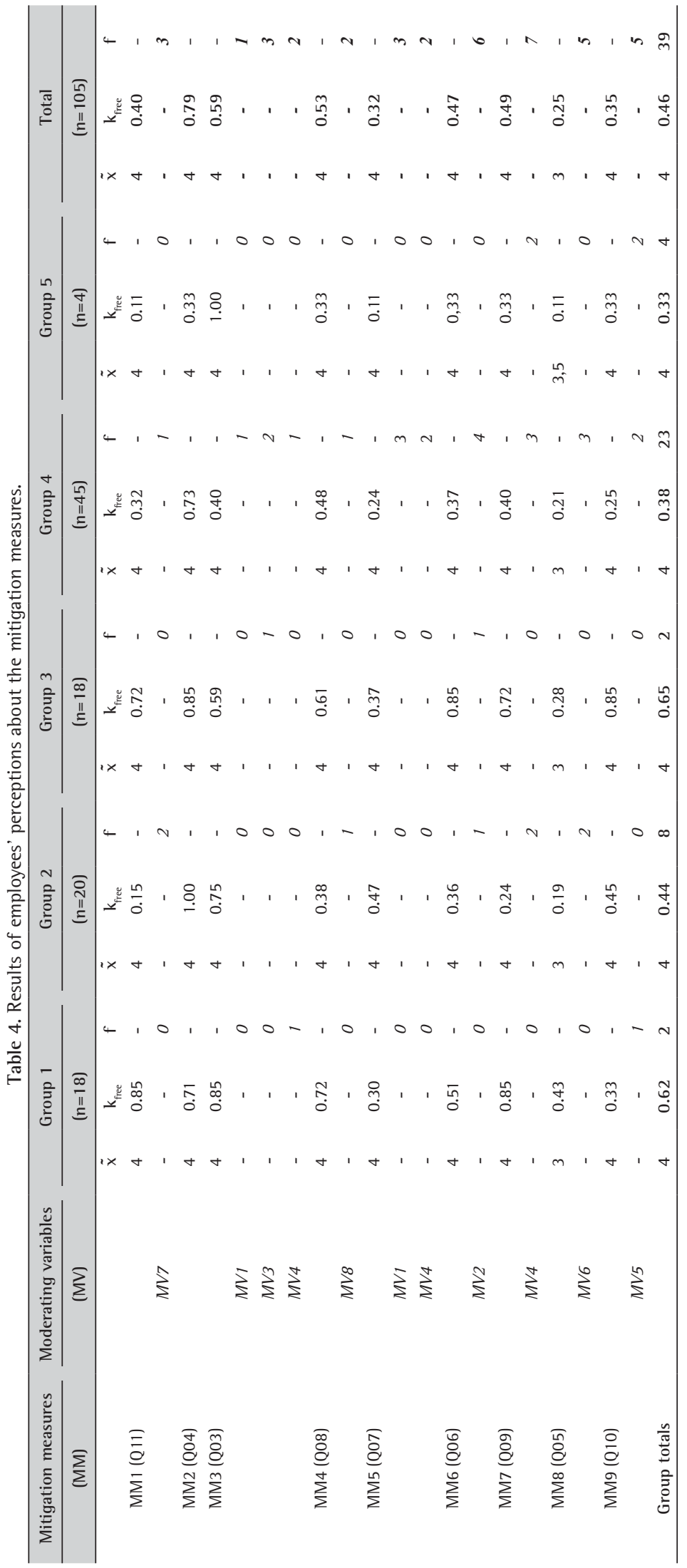


Table 5. Moderating variables.

\begin{tabular}{lcl}
\hline Code & Mitigation variable & \multicolumn{1}{c}{ Definition } \\
\hline MV1 & Agglomeration & $\begin{array}{l}\text { The concentrated number of employees resulting from poor visual communication about the safety } \\
\text { protocols. } \\
\text { Lack of discipline on the use of facemasks by in-office employees. } \\
\text { Questioning about the scope of the risk group applied by the company regarding the criteria compared } \\
\text { to those recommended by health authorities. }\end{array}$ \\
MV3 & Discipline on PPE use & The lack of inspection routines of safety protocols. \\
MV5 & Overtime & $\begin{array}{l}\text { The overtime performed by employees who kept working during the reduced production to make up for } \\
\text { the absence of the others. }\end{array}$ \\
MV6 & APP and Bl existence & The unaware of employees about the APP and Bl existence. \\
MV7 & CMT' role & The misunderstanding of the CMT's role within the organization. \\
MV8 & Temperature screening efficacy & An inaccurate trust level of the temperature measurement process was implemented.
\end{tabular}

Table 6. CIMO logic.

\begin{tabular}{llll}
\hline \multicolumn{1}{c}{ Context } & \multicolumn{1}{c}{ Intervention } & \multicolumn{1}{c}{ Mechanism } & \multicolumn{1}{c}{ Outcome } \\
\hline $\begin{array}{l}\text { Organization in general, } \\
\text { covering 100\% of employees, } \\
\text { subcontractors, and visitors. }\end{array}$ & MM1 - Crisis Management Team & $\begin{array}{l}\text { Daily meetings to analyze } \\
\text { scenarios and make contingency } \\
\text { decisions to mitigate risks. }\end{array}$ & $\begin{array}{l}\text { lncreased speed of the decision- } \\
\text { making process. }\end{array}$
\end{tabular}

Business travelers, employees on $\quad$ MM2 - Directives for travel international holidays, and any employee returning from corporate travelers. or private travel from risky areas. Organization in general, covering $100 \%$ of employees.

Organization in general, covering 100\% of employees, subcontractors, and visitors.

Fieldwork employees, subcontractors, and back-office workforce.

Employees exposed to a mid and high-risk level based on the Protocol applied to fieldwork.

Employees using chartered transport routes, and canteen.

Organization in general, covering $100 \%$ of employees.

Productions and Logistics areas. restriction and H\&S protocols for

MM3 - General Protocol for Health Procedures, routines, and Safety at work.

MM4 - Temperature screening.

MM5 - OHS Protocol for field and Rules, technical procedures, and 'in office' work.

MM6 - Protocol for N95 masks and other PPEs.

MM7 - Protocol for transportation Redesign of layouts, reduction and changes in the canteen lay-out.

MM8 - APP for tracking health self-assessment and B.l. dashboard.

MM9 - Temporary reduction in production level.
Travel restrictions, increased use of conference calls, suspension of management meetings requiring travel.

intensification of personal and collective hygiene, intensification of the home office regime in supporting areas, and classification of risk groups.

Daily measurements at the beginning of the workday and active search during working hours. guidelines.

The usage of N95 masks accordingly to the risk area.

Substantial reduction of business and private travels.

Clear guidelines for different scenarios, reduction of the number of employees at work, and strict hygiene routines within the organization.

Preventing symptomatic people from entering or remaining within the company.

Clear rules and procedures for safe work at job sites, and back-offices activities.

Protecting employees from airborne particles and liquid contaminating the face.

Absence of agglomerations on transport routes, and lunch hours. of available seats, and lunchtime extension.

Online monitoring of the health status of employees.

ldentification of initial symptoms status for intervention by occupational doctors and nurses.

$50 \%$ reduction in production levels Preparation and implementation of for two weeks. the new protocols to remain active.

Table 7. Comparative analysis of COVID 19 figures in 2020.

\begin{tabular}{|c|c|c|c|c|c|}
\hline \multirow{2}{*}{ Context } & \multirow{2}{*}{$\frac{\text { Normality test }}{\text { Kolmogorov-Smirnov }(n=311)}$} & \multicolumn{2}{|c|}{ Total cases/population (\% Ratio) } & \multicolumn{2}{|c|}{ Deaths/1M population } \\
\hline & & As of Jun $25^{\text {th }}$ & As of Dec $31^{\text {st }}$ & As of Jun $25^{\text {th }}$ & As of Dec $31^{\text {st }}$ \\
\hline Brazil & $\mathrm{D}=0.0871 ; p$-value $=5.5 \mathrm{e}-06$ & $0.58 \%$ & $3.65 \%$ & 261.5 & 927.6 \\
\hline State of Rio Grande do Sul & $\mathrm{D}=0.1965 ; \mathrm{p}$-value $<2.2 \mathrm{e}-16$ & $0.20 \%$ & $3.95 \%$ & 43.9 & 779.8 \\
\hline Case unit (Thyssenkrupp) & $\mathrm{D}=0.5347 ; \mathrm{p}$-value $<2.2 \mathrm{e}-16$ & $0.00 \%$ & $1.53 \%$ & 0 & 0 \\
\hline
\end{tabular}

Table 8. Non-parametric Kruskal-Wallis and Dunn post-hoc test analysis.

\begin{tabular}{|c|c|c|c|c|c|c|}
\hline \multirow{2}{*}{\multicolumn{2}{|c|}{ Kruskal-Wallis test }} & \multicolumn{5}{|c|}{ Dunn post-hoc test } \\
\hline & & \multirow{2}{*}{$\begin{array}{l}\mathrm{n} 1 \\
311\end{array}$} & \multirow{2}{*}{$\frac{\mathrm{n} 2}{311}$} & \multirow{2}{*}{$\frac{\text { Group } 1}{\mathrm{BR}}$} & \multirow{2}{*}{$\frac{\text { Group } 2}{\text { RS }}$} & \multirow{2}{*}{$\frac{\text { p-value adj. }}{0.377}$} \\
\hline Kruskal-Wallis chi-squared & 537.43 & & & & & \\
\hline $\mathrm{df}$ & 2 & 311 & 311 & BR & TK & $* * * *$ \\
\hline$p$-value & $<2.2 \mathrm{e}-16$ & 311 & 311 & RS & TK & $* * * *$ \\
\hline
\end{tabular}

\footnotetext{
***** Without significance.
} 
that official data underestimates the total number of cases, the results observed within the company demonstrate a much lower rate of cases for every 500 people when compared to Brazil and the state of Rio Grande do Sul. Second, there were no deaths among the employees while official data reported a significant number of people who died due to COVID-19.

The outcomes achieved based on the measures implemented also contributed to maintaining the level of delivering services and goods throughout the entire year of 2020. Based on the comparative analysis of the production level between april and december of the years 2019 and 2020 - the period in which the mitigation measures were implemented, no significant variation was observed according to statistical measures of dispersion (Figure 4). A monthly average of 327 elevators was produced in the selected period of 2019, while 333 were reported in the same period of 2020.

The coefficient of variation (CV based on standard deviation (SD) resulted in 10.8\% for the year 2019 and $11.5 \%$ for 2020 , representing equivalence in both periods. This equivalence was additionally confirmed by employing the T-test to confirm $\mathrm{HO}$ (there is no significant difference between means in both periods) that resulted in $p$-value significantly higher than 0.05 ( $p$-value $=0.9293$ ). With regards to normality tests, both tests Shapiro-Wilk and Komolgorov-Smirnov $(\alpha=0.05)$ confirmed the hypothesis HO (Normal distribution) and, thus, homogeneous data (Table 9). The volume of elevators produced is one of the most relevant KPI to evaluate the performance of the factory because it influences sales, productivity, and margin. During the period in which this research was conducted, surveillance agents audited the factory to assess the efficacy of the measures from the National Health System's perspective. Authorities also validated the business continuity recognizing the efficacy of the measures.

\section{Discussion}

To mitigate the health and economic impacts of COVID-19 within the organization, ThyssenKrupp Elevator's Brazil implemented a set of nine fast-response measures as presented in the previous section. Mitigation is the first stage in the Business continuity planning (Speight, 2011) and it needs to work in practice and not only in theory (Lindström et al., 2010). BCP is about managing risks based on an adequate and timely set of measures that need to be put in place to avoid all the threats associated with the emergency.

The context of COVID-19 in Brazil and particularly in the state of Rio Grande do Sul (where the factory is located) is shown in Figure 5. Since the first case was confirmed in the country on Feb 26th, 2020, the total accumulated cases increased significantly following an exponential curve. As of Jun $25^{\text {th }}$, 2020, a hundred twenty days since the first case was reported, official data reported 1.2 million cases and 54.971 deaths in Brazil. On Dec $31^{\text {st }}$, 2020, national figures accounted for more than 7.6 million accumulated total cases (3.7\% of the population) and almost 194,976 deaths. The state of Rio Grande do Sul reported a flatter curve due to local
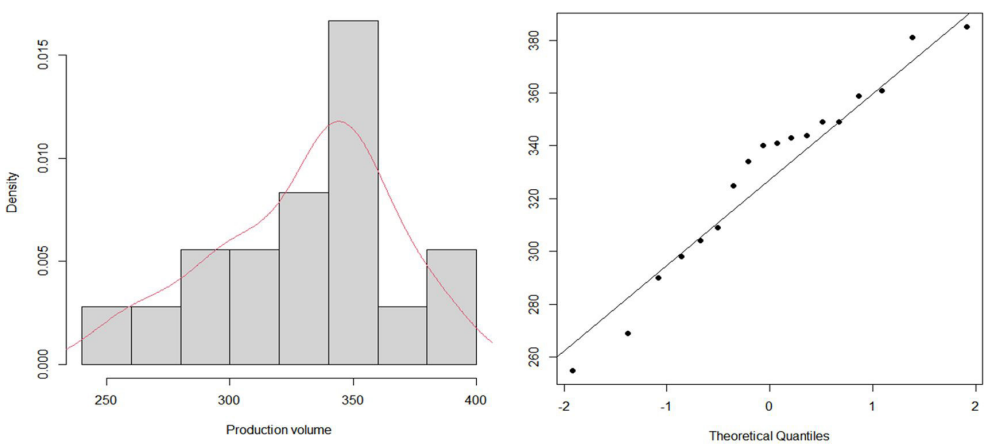

Figure 4. Histogram and QQ-Diagram for the production level (2019-2020).

Table 9. Comparative analysis of the level of production.

\begin{tabular}{cccccccc}
\hline \multirow{2}{*}{ Period } & \multirow{2}{*}{ Mea $\bar{x}$} & SD & \multirow{2}{*}{ CV } & \multicolumn{2}{c}{ Normality tests $(\boldsymbol{\alpha}=0.05)$} & Hypothesis test \\
\cline { 5 - 6 } & & & & Shapiro-Wilk & Kolmogorov-Smirnov & T-test $(2020 \sim 2019)$ \\
\hline $2019(\mathrm{n}=9)$ & 327 & 35.42 & $10.8 \%$ & $\mathrm{~W}=0.87166 \mathrm{p}$-value $=0.1281$ & $\mathrm{D}=0.24743 ; \mathrm{p}$-value $=0.1156$ & \\
$2020(\mathrm{n}=9)$ & 333 & 38.17 & $11.5 \%$ & $\mathrm{~W}=0.96231 \mathrm{p}$-value $=0.8222$ & $\mathrm{D}=0.13058 ; \mathrm{p}$-value $=0.9293$ & $\mathrm{p}$-value $=0.9293$ \\
$2019-2020(\mathrm{n}=18)$ & 330 & 35.86 & $10.9 \%$ & $\mathrm{~W}=0.95410 \mathrm{p}$-value $=0.4928$ & $\mathrm{D}=0.16775 ; \mathrm{p}$-value $=0.1986$ & \\
\hline
\end{tabular}




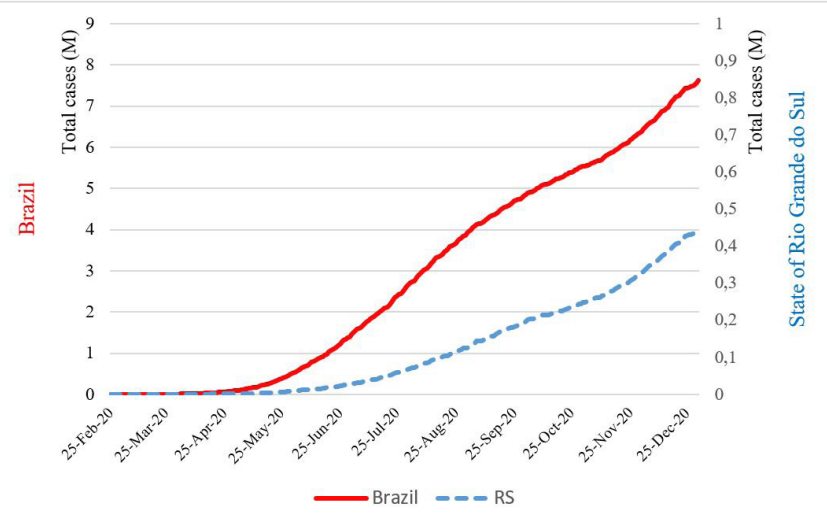

Figure 5. Accumulated confirmed cases in Brazil and the state of Rio Grande do Sul (RS) (Coronavirus Brasil, 2020).

measures early implemented by the government. Yet, throughout 2020 the number of cases reached 449,674 cases, which represents $4 \%$ of the population, a higher contagion rate than Brazil.

The Brazilian government's response was characterized by divergences among federal and state governments, contributing to the emergence of clusters within the country. While the state of São Paulo and major cities located in the north and northeast regions were dealing with critical situations on their public health services, in the state of Rio Grande do Sul, the spread of COVID-19 was flatted due to the local restrictions.

Several measures were promptly defined following the WHO (World Health Organization, 2020b) and Centers for Disease Control and Prevention (2020) to prepare, as possible, the mitigation measures to the National Health Sector. Additionally, a set of state decrees were defined to temporarily shut-down schools, trades, some non-essential industries as a massive social distancing recommendation. Organizations started to face an unprecedented challenge to mitigate COVID-19 from safety, health, and economic perspectives as Brazil moves towards becoming one of the pandemic epicenter (The Lancet, 2020).

With regards to the case unit, the measures were put in place to invalidate the assumptions of "the workplace is not safe enough against COVID-19" and "social distancing is the best way to prevent COVID-19". A hundred twenty days after the first confirmed case in Brazil, only one case of COVID-19, among the 520 employees working in person, was found while the state of Rio Grande do Sul reported more than 23,000 cases, in addition to the fact that the authorities recognize an inaccurate number of underreporting cases. Besides, from the employees' perspective, the mitigation measures were well accepted as indicated by the overall amplitude and level of agreement among respondents $\left(\tilde{x}=4\right.$ and $\left.k_{\text {free }}=0.46\right)$. These results not only indicate the invalidation of those two targeted assumptions, but also the need for improvement of WHO recommendations (World Health Organization, 2020b) from organizations' point of view.

With the three assumptions invalidated (Figure 6), the conflicting situation was broken, and it was possible to achieve the desired goal of "having the organization 100\% productive in a healthy and safe work environment". Also, from the CIMO logic, it was possible to infer that the main drivers leading to the results obtained so far are: (i) the speed of decision-making, (ii) the substantial reduction of business and private travels, (iii) the strict hygiene routines, (iv) the prevention of symptomatic people from entering or remaining within the company, (v) the clear rules and procedures for safe work, (vi) the adequate usage of PPEs, (vii) the absence of agglomerations, (viii) the online identification of initial symptoms status, and (ix) the rapid implementation of the new safety protocols. Although the overall indicators attest to the efficacy of the initiatives taken, there were some mitigation measures (MM1, MM5, MM8, and MM9) that only achieved a fair agreement among raters $\left(0.21 \geq k_{\text {free }} \leq 0.4\right)$. Considering the MM1 (Crisis Management Team - CMT), the content analysis revealed the MV7 (CMT's role), which suggests the need for wider internal communication within all organization's layers once some employees did not clearly understand the CMT's role. Regarding MM5 (OHS Protocol), two moderating variables emerged, MV1 and MV4. The MV1 (Agglomeration) indicates that better visual communication of the safety protocols should be carried out to avoid small agglomerations. The MV4 (Inspection routines), in turn, points out the need for increasing inspection routines of the protocol. In terms of MM8 (APP for tracking health self-assessment), the MV6 (APP and Bl existence) arose as a suggestion for improving the communication about the APP and Bl, since most of the employees were unaware of its existence. Finally, MM9 (Reduction in production level), gave rise to MV5 (Overtime), a contestation of the measured efficacy due to the overtime performed by those employees 


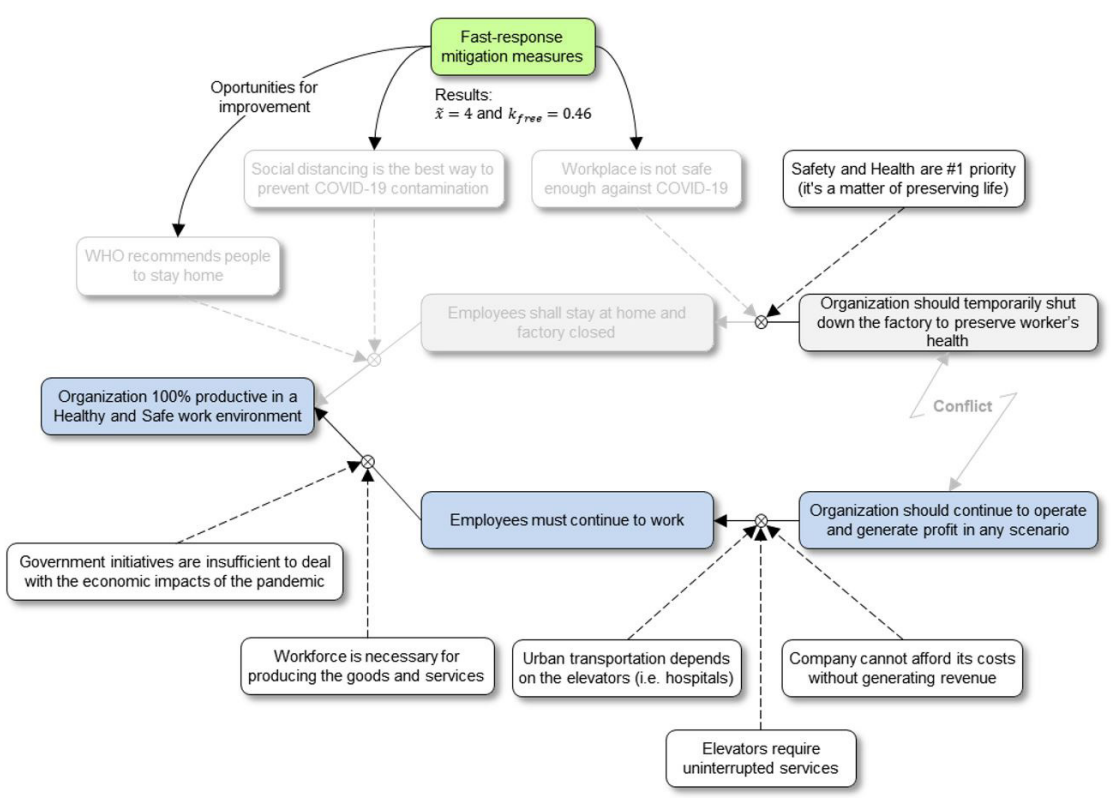

Figure 6. Assumptions invalidated by Mitigation Measures.

who kept working to make up for the absence of the others. All the opportunities for improvement identified through the MVs were used by the company for updating internal protocols and mitigating measures themselves.

The same pattern of a fair agreement $\left(0.21 \geq k_{\text {free }} \leq 0.4\right)$ was noted in the group axis. In this concern, Groups 4 and 5 presented discrepancies if compared to others. The reasons behind it lie in the fact the Group 4 accounts for the highest frequency of moderating variables (23 counts), and Group 5 presents a small sample size.

Overall, except for mitigation measures $\mathrm{MM} 1$ and $\mathrm{MM} 9$, the remaining ones are prone to remain in the company after the pandemic. That is because such an unprecedented scenario required significant changes that ended up creating a new work pattern within the organization. Also, empirical results attested to the efficacy of mitigation measures. First, because there was not a variation in the production level in the periods before and after COVID-19. Second, the organization remained the same, with no relevant changes in its number of employees. Third, since there is limited data available, when compared to official data, the rate of COVID cases within the organization is significantly lower than national and regional figures.

Given the resilience of these measures - the ability to remain economically and operationally viable after the peak of the pandemic - and the context in which they were implemented, these fast-response initiatives are being shared to the other sites of the Thyssenkrupp worldwide. Moreover, the measures also prepared the organization to keep operating under a second wave, which is already faced in Brazil. Because of that, we claim that they can be replicated to other organizations with similar boundary conditions and, additionally, validate the theoretical approach of Business Continuity Planning (BCP) to support organizations to deal with emergencies.

\section{Conclusion}

COVID-19 has imposed an unprecedented challenge to health systems, economies, organizations, and society worldwide. The speed and dynamics of the pandemic required short-term initiatives to keep the essential operations working safely. Since WHO (World Health Organization, 2020a) declared the COVID-19 outbreak as a pandemic, hundreds of papers on this subject have been published as a tentative to spread information on its implications to human health. However, most of these studies have been performed from a health perspective and consequently do not address the economic impacts of the COVID-19 pandemic.

The present research tried to bridge this gap by evaluating the efficacy of fast-response measures to mitigate the health and economic impacts of COVID-19 within the organizations. To do that this study used the concepts of the first stage of the Business Continuity Planning (BCP) and employed the Evaporating Cloud to support the analysis of how a multinational leading company in the elevator industry, located in Brazil, structured and broke this conflict by implementing a set of fast-response mitigation measures. The research findings indicate the mitigation measures implemented were well-accepted by employees and supported the decision-making 
process to maintain essential services and the production of goods at the same level of the period pre-COVID, providing a safe work environment even over the most critical period of the pandemic. In addition, a statistical comparative analysis of COVID-19 cases and production level attested to the efficacy of the set of measures taken.

In this context, the main contribution of this research lied in empirically presenting and investigating the efficacy of fast-response measures to deal with the trade-off imposed by COVID-19 at an enterprise-level. Besides that, additional conclusions were also possible. First, measures within the company are necessary, but not sufficient to guarantee the rates observed in the case unit. Therefore, the measures that the company adopted, hypothetically, may have contributed to increasing the employees' level of awareness beyond the work environment. Second, the behavior of workers and operational discipline in the face of the COVID-19 pandemic is an important element to be considered. Third, economic activity conducted under preventive measures that make sense to workers and rigorously followed can contribute to mitigating the effects of the pandemic on society. Fourth, the Evaporation Cloud has proven to be an effective mechanism for expanding the ability to analyze critical conflicts at the enterprise level, such as the COVID impacts.

Regarding the limitations, the following aspects are highlighted: (i) the research is based on a single case study conducted in a particular type of industry considered as an essential service and did not consider a probabilistic sampling, being only able to generalize its results analytically. Besides, official data about the economic impacts at an enterprise level is not available so far, preventing comparative analyzes between similar industries. (ii) the study was not carried out concerning workers working from home.

Despite the evaluation of the efficacy of these measures, further studies on the evaluation of effectiveness and efficiency in the area of OHSMS are necessary to adequately demonstrate the results of actions in this area in organizations.

\section{Acknowledgements}

The authors are grateful to The National Council for Scientific and Technological Development (CNPq) and Coordination for the Improvement of Higher Education Personnel (CAPES) for the support received to conduct this research.

\section{References}

Addo, P. C., Jiaming, F., Kulbo, N. B., \& Liangqiang, L. (2020). COVID-19: fear appeal favoring purchase behavior towards personal protective equipment. Service Industries Journal, 40(7-8), 471-490. http://dx.doi.org/10.1080/02642069.2020.1751823.

Ahmed, F., Zviedrite, N., \& Uzicanin, A. (2018). Effectiveness of workplace social distancing measures in reducing influenza transmission: a systematic review. BMC Public Health, 18(1), 518. http://dx.doi.org/10.1186/s12889-018-5446-1. PMid:29669545.

Andersen, S., Gupta, M., \& Gupta, A. (2013). A managerial decision-making web app: Goldratt's evaporating cloud. International Journal of Production Research, 51(8), 2505-2517. http://dx.doi.org/10.1080/00207543.2012.743687.

Anderson, R. M., Heesterbeek, H., Klinkenberg, D., \& Hollingsworth, T. D. (2020). How will country-based mitigation measures influence the course of the COVID-19 epidemic? Lancet, 395(10228), 931-934. http://dx.doi.org/10.1016/S0140-6736(20)30567-5. PMid:32164834.

Arora, A. K., \& Srinivasan, R. (2020). Impact of pandemic covid-19 on the teaching - learning process: A study of higher education teachers. Prabandhan: Indian Journal of Management., 13(4), 43-56. http://dx.doi.org/10.17010/pijom/2020/v13i4/151825.

Bardin, L. (1993). L'analyse de contenu. Paris: Presses Universitaires de France Le Psychologue.

Barratt, M., Choi, T. Y., \& Li, M. (2011). Qualitative case studies in operations management: Trends, research outcomes, and future research implications. Journal of Operations Management, 29(4), 329-342. http://dx.doi.org/10.1016/j.jom.2010.06.002.

Beeler, M. F., Aleman, D. M., \& Carter, M. W. (2011). Estimation and management of pandemic influenza transmission risk at mass immunization clinics. In S. Jain, R. R. Creasey, J. Himmelspach, K. P. White, \& M. Fu (Eds.), Proceedings of the 2011 Winter Simulation Conference (pp. 1117-1124). USA: IEEE. http://dx.doi.org/10.1109/WSC.2011.6147834.

Blendon, R. J., Koonin, L. M., Benson, J. M., Cetron, M. S., Pollard, W. E., Mitchell, E. W., Weldon, K. J., \& Herrmann, M. J. (2008). Public response to community mitigation measures for pandemic influenza. Emerging Infectious Diseases, 14(5), 778-786. http:// dx.doi.org/10.3201/eid1405.071437. PMid:18439361.

Borodziz, E. P. (2005). Risk, crisis and security management. West Sussex, England: Wiley.

Brasil (2020). Decreto n. 10.329. Presidência da República: Brasilia, DF.

Bruinen de Bruin, Y., Lequarre, A. S., McCourt, J., Clevestig, P., Pigazzani, F., Zare Jeddi, M., Colosio, C., \& Goulart, M. (2020). Initial impacts of global risk mitigation measures taken during the combatting of the COVID-19 pandemic. Safety Science, 128, 104773. http://dx.doi.org/10.1016/j.ssci.2020.104773. PMid:32296266.

Cauchick Miguel, P. A. (2012). Metodologia de pesquisa para engenharia de produção e gestão de operações. (2. ed.). USA: Eselvier.

Centers for Disease Control and Prevention - CDC. (2020). Pandemic preparedness resources. Washington: CDC. Retrieved in 2020, May 28, from https://www.cdc.gov/coronavirus/2019-ncov/php/pandemic-preparedness-resources.html

Cerullo, V., \& Cerullo, M. J. (2004). Business continuity planning: A comprehensive approach. Information Systems Management, 21(3), 70-78. http://dx.doi.org/10.1201/1078/44432.21.3.20040601/82480.11. 
Charania, N., \& Tsuji, L. (2014). Recommended mitigation measures for an influenza pandemic in remote and isolated First Nations communities of Ontario, Canada: a community-based participatory research approach. International Indigenous Policy Journal, 5(3). http://dx.doi.org/10.18584/iipj.2014.5.3.2.

Ciofi degli Atti, M. L., Merler, S., Rizzo, C., Ajelli, M., Massari, M., Manfredi, P., Furlanello, C., Scalia Tomba, G., \& lannelli, M. (2008). Mitigation measures for pandemic influenza in ltaly: An individual based model considering different scenarios. PLoS One, 3(3), e1790. http://dx.doi.org/10.1371/journal.pone.0001790. PMid:18335060.

Coronavírus Brasil. (2020). COVID-19 - Painel Coronavirus. Retrieved in 2020, May 10, from https://covid.saude.gov.br

Cui, J., Li, F., \& Shi, Z. L. (2019). Origin and evolution of pathogenic coronaviruses. Nature Reviews. Microbiology, 17(3), 181-192. http://dx.doi.org/10.1038/s41579-018-0118-9. PMid:30531947.

Dargaville, T., Spann, K., \& Celina, M. (2020). Opinion to address the personal protective equipment shortage in the global community during the COVID-19 outbreak. Polymer Degradation \& Stability, 176, 109162. http://dx.doi.org/10.1016/j.polymdegradstab.2020.109162. PMid:32292217.

De Vos, J. (2020). The effect of COVID-19 and subsequent social distancing on travel behavior. Transportation Research Interdisciplinary Perspectives, 5, 100121. http://dx.doi.org/10.1016/j.trip.2020.100121.

Deephti, N., Masthi, N. R. R., Nirmala, C. J., Manjula, R., \& Vinothkumar, S. (2020). Personal protective equipments (Ppe) - prerequisites, rationale and challenges during COVID 19 pandemic. Indian Journal of Community Health, 32(2), 196-205. Retrieved in 2020, May 10, from https://www.scopus.com/inward/record.uri?eid=2-s2.0-85083772583\&partnerlD=40\&md5=3a048790fb9ca0d5edd 903a66bd195a7

Denyer, D., Tranfield, D., \& van Aken, J. E. (2008). Developing design propositions through research synthesis. Organization Studies, 29(2), 249-269. http://dx.doi.org/10.1177/0170840607088020.

Eidelwein, F., Piran, F. A. S., Lacerda, D. P., Dresch, A., \& Rodrigues, L. H. (2017). Exploratory analysis of modularization strategy based on the theory of constraints thinking process. Global Journal of Flexible Systems Management., 9, 111-122. http://dx.doi. org/10.1007/s40171-017-0177-1.

Fong, M., Gao, H., Wong, J. Y., Xiao, J., Shiu, E. Y. C., Ryu, S., \& Cowling, B. J. (2020). Nonpharmaceutical measures for pandemic influenza in nonhealthcare settings-social distancing measures. Emerging Infectious Diseases, 26(5), 976-984. http://dx.doi. org/10.3201/eid2605.190995. PMid:32027585.

Forza, C. (2002). Survey research in operations management: A process-based perspective. International Journal of Operations \& Production Management, 22(2), 152-194. http://dx.doi.org/10.1108/01443570210414310.

Goldratt, E. M. (1990). What is this thing called theory of constraints and how should it be implemented?. Croton-on-Hudson, NY: North River Press.

Holland, M., Zaloga, D. J., \& Friderici, C. S. (2020). COVID-19 Personal Protective Equipment (PPE) for the emergency physician. Visual Journal of Emergency Medicine., 19, 100740. http://dx.doi.org/10.1016/j.visj.2020.100740. PMid:32289084.

Huang, C., Wang, Y., Li, X., Ren, L., Zhao, J., Hu, Y., Zhang, L., Fan, G., Xu, J., Gu, X., Cheng, Z., Yu, T., Xia, J., Wei, Y., Wu, W., Xie, X., Yin, W., Li, H., Liu, M., Xiao, Y., Gao, H., Guo, L., Xie, J., Wang, G., Jiang, R., Gao, Z., Jin, Q., Wang, J., \& Cao, B. (2020). Clinical features of patients infected with 2019 novel coronavirus in Wuhan, China. Lancet, 395(10223), 497-506. http://dx.doi.org/10.1016/ S0140-6736(20)30183-5. PMid:31986264.

Imperial College London. (2020). Short-term forecasts of COVID-19 deaths in multiple countries. London: Imperial College London. Retrieved in 2020, May 10, from https://mrc-ide.github.io/covid19-short-term-forecasts/index.html

Ivanov, D., \& Dolgui, A. (2020). Viability of intertwined supply networks: extending the supply chain resilience angles towards survivability. A position paper motivated by COVID-19 outbreak. International Journal of Production Research, 58(10), 2904-2915. http://dx.doi. org/10.1080/00207543.2020.1750727.

Kamel Boulos, M. N., \& Geraghty, E. M. (2020). Geographical tracking and mapping of coronavirus disease COVID-19/severe acute respiratory syndrome coronavirus 2 (SARS-CoV-2) epidemic and associated events around the world: how 21st century GIS technologies are supporting the global fight against outbreak. International Journal of Health Geographics, 19(1), 8. http://dx.doi.org/10.1186/ s12942-020-00202-8. PMid:32160889.

Kazemzadeh, R. B., Behzadian, M., Aghdasi, M., \& Albadvi, A. (2009). Integration of marketing research techniques into house of quality and product family design. International Journal of Advanced Manufacturing Technology, 41(9-10), 1019-1033. https:// doi.org/10.1007/s00170-008-1533-2.

Kim, R. Y. (2020). The impact of COVID-19 on consumers: preparing for digital sales. IEEE Engineering Management Review, 48(3), 212-218. http://dx.doi.org/10.1109/EMR.2020.2990115.

Kim, S., Mabin, V. J., \& Davies, J. (2008). The theory of constraints thinking processes: retrospect and prospect. International Journal of Production Research, 28(2), 155-184. http://dx.doi.org/10.1108/01443570810846883.

Kuckertz, A., Brändle, L., Gaudig, A., Hinderer, S., Morales Reyes, C. A., Prochotta, A., Steinbrink, K. M., \& Berger, E. S. C. (2020). Startups in times of crisis - A rapid response to the COVID-19 pandemic. Journal of Business Venturing Insights., 13, e00169. http://dx.doi. org/10.1016/j.jbvi.2020.e00169.

Landis, J. R., \& Koch, G. G. (1977). The measurement of observer agreement for categorical data. Biometrics, 33(1), 159-174. http:// dx.doi.org/10.2307/2529310. PMid:843571.

Lindström, J., Samuelsson, S., \& Hägerfors, A. (2010). Business continuity planning methodology. Disaster Prevention and Management, 19(2), 243-255. http://dx.doi.org/10.1108/09653561011038039.

Mackenzie, J., \& Smith, D. (2020). COVID-19: a novel zoonotic disease caused by a coronavirus from China: what we know and what we don't. Microbiology Australia, 17, MA20013. Ahead of print. http://dx.doi.org/10.1071/MA20013. PMid:32226946.

Malhotra, N. K., \& Birks, D. F., (2007). Marketing research: an applied approach (3rd ed.). Upper Saddle River, Nova Jersey: Prentice Hall Inc. http://dx.doi.org/10.1108/S1548-6435(2007)3.

Montgomery, D. C., \& Runger, G. C. (2011). Applied statistics and probability for engineers (3rd ed.). Hoboken: John Wiley \& Sons, Ltd. 
Morandi, M. I. W. M., \& Camargo, L. F. R. (2015). Systematic literature review. In A. Dresch, D. P. Lacerda \& J. A. V. Antunes Jr, Design science research (pp. 161). New York: Springer.

Pacheco Lacerda, D., Augusto Cassel, R., \& Henrique Rodrigues, L. (2010). Service process analysis using process engineering and the theory of constraints thinking process. Business Process Management Journal, 16(2), 264-281. http://dx.doi.org/10.1108/14637151011035598.

Qualls, N., Levitt, A., Kanade, N., Wright-Jegede, N., Dopson, S., Biggerstaff, M., Reed, C., Uzicanin, A., Levitt, A., Dopson, S., Frank, M., Holloway, R., Koonin, L., Rasmussen, S., Redd, S., de la Motte Hurst, C., Kanade, N., Qualls, N., Rainey, J., Uzicanin, A., Biggerstaff, M., Jernigan, D., \& Reed, C., \& CDC Community Mitigation Guidelines Work Group. (2017). Community mitigation guidelines to prevent pandemic influenza - United States, 2017. MMWR. Recommendations and Reports, 66(1), 1-34. http://dx.doi.org/10.15585/ mmwr.rr6601a1. PMid:28426646.

Randolph, J. J. (2005, October 14-15). Free-marginal multirater kappa: an alternative to Fleiss' fixed-marginal multirater kappa. In Joensuu University Learning and Instruction Symposium. Joensuu, Finland: Retrieved in 2020, May 8, from https://files.eric.ed.gov/ fulltext/ED490661.pdf.

Shim, E., Tariq, A., Choi, W., Lee, Y., \& Chowell, G. (2020). Transmission potential and severity of COVID-19 in South Korea. International Journal of Infectious Diseases : IJID : Official Publication of the International Society for Infectious Diseases, 93, 339-344. http:// dx.doi.org/10.1016/j.jij.2020.03.031. PMid:32198088.

Sobieralski, J. B. (2020). COVID-19 and airline employment: insights from historical uncertainty shocks to the industry. Transportation Research Interdisciplinary Perspectives, 5, 100123. http://dx.doi.org/10.1016/j.trip.2020.100123.

Speight, P. (2011). Business continuity. Journal of Applied Security Research, 6(4), 529-554. http://dx.doi.org/10.1080/19361610.20 11.604021.

Su, S., Wong, G., Shi, W., Liu, J., Lai, A. C. K., Zhou, J., Liu, W., Bi, Y., \& Gao, G. F. (2016). Epidemiology, genetic recombination, and pathogenesis of coronaviruses. Trends in Microbiology, 24(6), 490-502. http://dx.doi.org/10.1016/j.tim.2016.03.003. PMid:27012512.

The Lancet. (2020). COVID-19 in Brazil: “ So what?.” [Editorial]. The Lancet, 395(10235), 1461. http://dx.doi.org/10.1016/S01406736(20)31095-3.

Thyssenkrupp Elevator. (2020). Retrieved in 2020, April 28, from www.thyssenkruppelevadores.com.br

Tsukui, S. (2012). Case-based surveillance of pandemic (H1N1) 2009 in Maebashi City, Japan. Japanese Journal of Infectious Diseases, 65(2), 132-137. PMid:22446120.

van Aken, J., Chandrasekaran, A., \& Halman, J. (2016). Conducting and publishing design science research: Inaugural essay of the design science department of the Journal of Operations Management. Journal of Operations Management, 47-48(1), 1-8. http:// dx.doi.org/10.1016/j.jom.2016.06.004.

Veit, D., Lacerda, D. P., Camargo, L. F. R., Kipper, L. M., \& Dresch, A. (2017). Towards Mode 2 knowledge production. Business Process Management Journal, 23(2), 293-328. http://dx.doi.org/10.1108/BPMJ-03-2016-0045.

Weiss, S. R., \& Leibowitz, J. L. (2011). Coronavirus pathogenesis. Advances in Virus Research, 81, 85-164. http://dx.doi.org/10.1016/ B978-0-12-385885-6.00009-2. PMid:22094080.

Worldmeter. (2020). COVID-19 Coronavirus pandemic. Retrieved in 2020, May 10, from https://worldmeters.info/coronavirus

World Health Organization - WHO. (2020a). Coronavirus disease (COVID-19) pandemic. Retrieved in 2020, May 10, from https://www. who.int/emergencies/diseases/novel-coronavirus-2019

World Health Organization - WHO. (2020b). Get your workplace ready for COVID-19. Retrieved in 2020, April 28, from https://www. who.int/who-documents-detail/getting-your-workplace-ready-for-covid-19-how-covid-19-spreads

Wu, C., Chen, X., Cai, Y., Xia, J., Zhou, X., Xu, S., Huang, H., Zhang, L., Zhou, X., Du, C., Zhang, Y., Song, J., Wang, S., Chao, Y., Yang, Z., Xu, J., Zhou, X., Chen, D., Xiong, W., Xu, L., Zhou, F., Jiang, J., Bai, C., Zheng, J., \& Song, Y. (2020). Risk factors associated with acute respiratory distress syndrome and death in patients with coronavirus disease 2019 pneumonia in Wuhan, China. JAMA Internal Medicine, 180(7), 934-943. http://dx.doi.org/10.1001/jamainternmed.2020.0994. PMid:32167524.

Yin, R. K. (2018). Case study research and applications: design and methods (6th ed.). Thousand Oaks, Califómia, EUA: Sage Publications, Inc.

Yu, K. D. S., \& Aviso, K. B. (2020). Modelling the economic impact and ripple effects of disease outbreaks. Process Integration and Optimization for Sustainability, 4, 183-186. http://dx.doi.org/10.1007/s41660-020-00113-y.

Zaki, A. M., van Boheemen, S., Bestebroer, T. M., Osterhaus, A. D. M. E., \& Fouchier, R. A. M. (2012). Isolation of a novel coronavirus from a man with pneumonia in Saudi Arabia. New England Journal of Medicine, 367, 1814-1820. http://dx.doi.org/10.1056/ NEJMoa1211721.

Zhong, N. S., Zheng, B. J., Li, Y. M., Poon, L. L. M., Xie, Z. H., Chan, K. H., Li, P. H., Tan, S. Y., Chang, Q., Xie, J. P., Liu, X. Q., Xu, J., Li, D. X., Yuen, K. Y., Peiris, J. S. M., \& Guan, Y. (2003). Epidemiology and cause of severe acute respiratory syndrome (SARS) in Guangdong, People's Republic of China, in February, 2003. Lancet, 362(9393), 1353-1358. http://dx.doi.org/10.1016/S01406736(03)14630-2. PMid:14585636.

Zhou, Y., Yang, G. D., Feng, K., Huang, H., Yun, Y. X., Mou, X. Y., \& Wang, L. F. (2020). Clinical features and chest CT findings of coronavirus disease 2019 in infants and young children. Chinese Journal of Contemporary Pediatrics., 22(3), 215-220. PMid:32204756.

Zhu, N., Zhang, D., Wang, W., Li, X., Yang, B., Song, J., Zhao, X., Huang, B., Shi, W., Lu, R., Niu, P., Zhan, F., Ma, X., Wang, D., Xu, W., Wu, G., Gao, G. F., \& Tan, W., \& China Novel Coronavirus Investigating and Research Team (2020). A novel coronavirus from patients with pneumonia in China, 2019. The New England Journal of Medicine, 382(8), 727-733. http://dx.doi.org/10.1056/ NEJMoa2001017. PMid:31978945. 


\section{Appendix A - Online Questionaire}

Q1 Please inform your department.

o Administrative or Commercial (HR, Legal, Purchasing, Quality, and Sales

o Engineering (industrial, projects, technical support, specification)

o Management (Coordinators, Managers, and Directors)

o Production and Logistics

\section{o Others}

Q2 Please select the time you have been work for Thyssenkrupp.

o More than 15 years

o 8-15 years

o 2-8 years

o Less than 2 years

Q3 To what extent do you agree or disagree the general protocol adopted by the company to guide employees about COVID-19, establish new operational routines such as the Home Office regime, definition of Risk Groups, new hygiene standards, among other measures, allowed the continuity of work under health and safety conditions at work.

o Fully disagree (1)

o Partially disagree (2)

o Partially agree (3)

o Fully agree (4)

J.Q3 Regarding the previous question, in case of Fully disagree (1) or Partially disagree (2), please inform the reasons.

Q4 To what extent do you agree or disagree the Directives for restricting domestic and international travels, including the establishment of quarantine for travelers returning from countries considered critical to COVID-19, were adequate measures to avoid the risk of contagion and ensure the safety of active employees.

o Fully disagree (1)

o Partially disagree (2)

o Partially agree (3)

o Fully agree (4)

J.Q4 Regarding the previous question, in case of Fully disagree (1) or Partially disagree (2), please inform the reasons.

Q5 To what extent do you agree or disagree he online health questionnaire (APP COVID-19) developed by the IT team to monitor daily the employee self-assessment represents a measure that has contributed to ensuring the company's healthy environment.

o Fully disagree (1)

o Partially disagree (2)

o Partially agree (3)

o Fully agree (4)

J.Q5 Regarding the previous question, in case of Fully disagree (1) or Partially disagree (2), please inform the reasons.

Q6 To what extent do you agree or disagree the specification of new PPEs such as N95 masks or 3-layer (surgical) facemasks and Face shields allowed a higher level of safety in the work environment preventing COVID-19.

o Fully disagree (1)

o Partially disagree (2)

o Partially agree (3)

o Fully agree (4)

J.Q6 Regarding the previous question, in case of Fully disagree (1) or Partially disagree (2), please inform the reasons.

Q7 To what extent do you agree or disagree the protocol that regulates fieldwork areas (e.g. at job sites) and the protocol for administrative work (in office) established appropriate criteria so that the employee feels safer 
concerning contagion by a coronavirus.

o Fully disagree (1)

o Partially disagree (2)

o Partially agree (3)

o Fully agree (4)

J.Q7 Regarding the previous question, in case of Fully disagree (1) or Partially disagree (2), please inform the reasons.

Q8 To what extent do you agree or disagree with the company's decision to take daily temperature measurements for $100 \%$ of employees is an important preventive measure for COVID-19 and provides a safer work environment.

o Fully disagree (1)

o Partially disagree (2)

o Partially agree (3)

o Fully agree (4)

J.Q8 Regarding the previous question, in case of Fully disagree (1) or Partially disagree (2), please inform the reasons.

Q9 To what extent do you agree or disagree the alteration of the canteen layout, including the extension of lunch hours and stricter hygiene rules, represents a measure directly related to the prevention of coronavirus and the safe work environment,

o Fully disagree (1)

o Partially disagree (2)

o Partially agree (3)

o Fully agree (4)

J.Q9 Regarding the previous question, in case of Fully disagree (1) or Partially disagree (2), please inform the reasons. Q10 To what extent do you agree or disagree the decision to temporarily reduce production on March 16, contributed to social distance, reducing the number of active employees in person and allowed the company to take appropriate measures to ensure a safe work environment in the economic recovery.

o Fully disagree (1)

o Partially disagree (2)

o Partially agree (3)

o Fully agree (4)

J.Q10 Regarding the previous question, in case of Fully disagree (1) or Partially disagree (2), please inform the reasons.

Q11 To what extent do you agree or disagree the Crisis Committee has been instrumental in defining effective mitigation measures against the spread of COVID-19 in the company.

o Fully disagree (1)

o Partially disagree (2)

o Partially agree (3)

o Fully agree (4)

J.Q11 Regarding the previous question, in case of Fully disagree (1) or Partially disagree (2), please inform the reasons. 